\title{
OPTIMASI FORMULA PADA GRANUL PARACETAMOL DENGAN VARIASI KOMPOSISI BAHAN PENGISI LAKTOSA DAN AVICEL PH 101 SERTA EVALUASI PARAMETER KADAR LEMBAB MOISTURE CONTENT DAN LOSS ON DRYING
}

\author{
Annisa Fatmawati ${ }^{1 *}$, Emelda ${ }^{2}$, Azza Elvana $^{3}$ \\ ${ }^{1}$ Program Studi Sarjana Farmasi; Fakultas IImu-IImu Kesehatan; Universitas Alma Ata \\ ${ }^{2}$ Program Studi Sarjana Farmasi; Fakultas IImu-IImu Kesehatan; Universitas Alma Ata \\ ${ }^{3}$ Laboratorium Teknologi Farmasi; Fakultas IImu-Ilmu Kesehatan; Universitas Alma Ata \\ Email: annisafatma20@almaata.ac.id, emelda@almaata.ac.id, elvanaazza@gmail.com \\ Korespondensi: \\ Annisa Fatmawati \\ Program Studi Sarjana Farmasi, Fakultas Ilmu-IImu Kesehatan, Universitas Alma Ata \\ Email Korespondensi: annisafatma20@almaata.ac.id
}

\begin{abstract}
Abstrak
Industri Farmasi selalu melakukan penelitian dan pengembangan formula obat, dimana untuk mendapatkan sediaan farmasetis yang berkualitas sesuai dengan CPOB. Paracetamol merupakan obat yang berkhasiat sebagai analgetik dan antipiretik, dalam sediaan padat berupa sediaan tablet yang diformulasikan dengan metode granulasi basah. Penelitian ini bertujuan untuk mengetahui kandungan lembab berupa parameter MC (Moisture Content) dan LOD (Loss on Drying) pada granul paracetamol dengan variasi bahan pengisi laktosa dan avicel PH 101. Metode penelitian ini menggunakan metode gravimetri dengan membuat granul paracetamol dan menguji kandungan lembab pada menit ke- 15 , 30, 60, 120 dan 180 pengeringan. Hasil penelitian menunjukkan bahwa Formula I (100\% Laktosa) dan Formula III (50\% Laktosa dan 50\% avicel PH 101) memiliki kandungan lembab $<3 \%$ pada menit ke 120 , sedangkan Formula II (100\% avicel PH 101) memiliki kandungan lembab $<3 \%$ dinyatakan dengan LOD $(2,52 \%)$ dan MC $(2,58 \%)$ pada menit ke-60. Formula II merupakan formula yang paling baik untuk digunakan dalam formulasi sediaan tablet paracetamol dengan metode granulasi basah berdasarkan kandungan lembab MC dan LOD.
\end{abstract}

Kata Kunci: loss on drying; moisture content; paracetamol

\section{FORMULA OPTIMIZATION OF GRANUL PARACETAMOL WITH VARIATION OF LACTOSA FILLERS AND AVICEL PH 101 WITH MOISTURE CONTENT AND LOSS ON DRYING MOISTURE CONTENT PARAMETERS}

\begin{abstract}
The Pharmaceutical Industry always conducts research and development of medicinal formulas, which is to obtain quality pharmaceutical preparations. Paracetamol is a drug that has analgesic and antipyretic properties, in a solid form in the form of a tablet formulated by the wet granulation method. This study aims to determine the moisture content in the form of MC (Moisture Content) and LOD (LOSS on Drying) parameters in paracetamol granules with variations of lactose and avicel PH 101 fillers. This research method uses the gravimetric method by making paracetamol granules and testing the moisture content in minutes. 15th, 30th, 60th, 120th and 180th drying. The results showed that Formula I (100\% Lactose) and Formula III (50\% Lactose: 50\% avicel PH101) had moisture content $<3 \%$ at 120 minutes, while Formula II (100\% avicel PH 101) had moisture content $<3 \%$. expressed
\end{abstract}


by LOD $(2.52 \%)$ and $M C(2.58 \%)$ at the $60^{\text {th }}$ minute. Formula II is the best formula for use in the formulation of paracetamol tablets using the wet granulation method based on the moisture content of MC and LOD.

Keywords: loss on drying; moisture content; paracetamol

\section{PENDAHULUAN}

Industri farmasi di Indonesia tersebar luas di berbagai provinsi, dimana rata-rata mereka memproduksi sediaan tablet paracetamol. Paracetamol merupakan obat dengan efek farmakologi sebagai analgetika dan antipiretika. Paracetamol diproduksi dalam jumlah banyak dan harga relatif terjangkau oleh masyarakat Indonesia. Industri farmasi dalam memproduksi sediaan obat paracetamol tablet selalu melakukan inovasi dan pengembangan produk untuk menghasilkan produk yang memiliki kualitas sesuai dengan persyaratan $\mathrm{CPOB}$ (Cara Pembuatan Obat yang Baik) ${ }^{1}$.

Sediaan tablet paracetamol diproduksi dengan metode granulasi basah. Granulasi basah (aglomerasi) merupakan teknologi formulasi dengan cara pengadukan (agitasi) serbuk atau campuran serbuk dengan keberadaan cairan sebagai bahan pengikat yang dicampurkan dengan serbuk kering ${ }^{2}$. Granul adalah suatu produk yang dihasilkan melalui proses granulasi. Granul tidak hanya merupakan produk antara pada proses pembuatan tablet, akan tetapi juga dapat menjadi sediaan obat tersendiri. Bahan yang dibutuhkan dalam pembuatan granulasi basah paracetamol, yaitu bahan pengisi, bahan pengikat, bahan penghancur dan bahan pelicin ${ }^{3}$. Pada penelitian ini akan diteliti pengaruh bahan pengisi laktosa dan avicel PH 101 terhadap kualitas granul dengan parameter kandungan lembab LOD (Loss on Drying) dan MC (Moisture Content). Bahan pengisi berfungsi memperbaiki sifat alir dan berfungsi sebagai bahan pengikat sehingga dapat dengan mudah dikempa atau memacu aliran ${ }^{4}$.

\section{METODE PENELITIAN}

\section{Alat dan Bahan}

Alat yang digunakan pada penelitian ini yaitu timbangan analitik (ACIS AD-600i), cawan porselen, mortir \& stamper, ayakan mesh 12 , loyang, cawan petri dan oven (Memmert UN55). Bahan yang digunakan yaitu serbuk parasetamol (USP 35 GRADE), Laktosa, Avicel PH 101, Amprotab, PVP (Polivinyl Pirolidon), Mg Stearat.

\section{Rancangan Penelitian}

Penelitian ini dilaksanakan di Laboratorium Teknologi Farmasi, Fakultas IImu- 
Ilmu Kesehatan, Universitas Alma Ata, Yogyakarta. Metode penelitian kualitas granul ini menggunakan metode gravimetri. Pembuatan granul paracetamol mengguanakan granulasi basah dilakukan dengan mencampurkan seluruh bahan yang ada pada Tabel 1, membuat granul paracetamol dengan ayakan mesh 12 dan menguji kandungan lembab pada menit ke- $15,30,60,120$ dan 180 pengeringan ${ }^{3}$. Penelitian ini menggunakan parameter pernyataan kadar lembab LOD dan MC.

Tabel I. Formula Granul Paracetamol Dengan Variasi Komposisi Bahan Pengisi Laktosa Dan Avicel PH 101

\begin{tabular}{cccc}
\hline Nama bahan & Formula I (mg) & Formula II (mg) & Formula III (mg) \\
\hline Paracetamol & 500 & 500 & 500 \\
Laktosa & 95 & - & 47,5 \\
Avicel PH 101 & - & 95 & 47,5 \\
Amprotab & 30 & 30 & 30 \\
PVP & 20 & 20 & 20 \\
Mg Stearat & 5 & 5 & 5 \\
Total Bobot tablet & 650 & 650 & 650 \\
\hline
\end{tabular}

\section{a. Loss on Drying (LOD)}

Suatu pernyataan kadar kelembaban berdasarkan bobot basah. Granul basah yang akan dikeringkan dan yang telah dikeringkan pada masing-masing waktu, ditimbang dan dihitung LOD dengan rumus sebagai berikut:

$\%$ LOD = $(((\text { Bobot granul basah-Bobot granul kering }) / \text { Bobot granul basah }) \times 100 \%)^{5}$

\section{b. Moisture Content (MC)}

Suatu pernyataan kandungan lembab berdasarkan bobot kering atau dikenal dengan istilah uji susut pengeringan ${ }^{3}$. Granul basah yang akan dikeringkan dan yang telah dikeringkan pada masing-masing waktu, ditimbang dan dihitung MC. Rumus perhitungan $\mathrm{MC}$ sebagai berikut, \% MC = (((Bobot granul basah - Bobot granul kering $) /$ Bobot granul kering) x 100\%).

\section{HASIL DAN PEMBAHASAN}

\section{Pembuatan Granul Parasetamol dengan Granulasi Basah}

Bahan aktif obat dan bahan tambahan yang terdapat pada Tabel I, ditimbang sejumlah bahan untuk 100 tablet. Selanjutnya mencampurkan paracetamol dengan amprotab, bahan pengisi sesuai Formula I, II dan III menggunakan mortir dan stamper. Campuran homogen dalam mortir tersebut, ditambahkan PVP yang dibuat mucilago dan diaduk hingga homogen. 
Optimasi Formula pada Granul Paracetamol dengan Variasi Komposisi Bahan Pengisi Laktosa dan Avicel PH 101 Serta Evaluasi Parameter Kadar Lembab Moisture Content dan Loss on Drying

Kemudian dilakukan uji banana breaking test untuk memastikan massa tersebut siap untuk digranulasi. Massa granul dicetak menggunakan ayakan mesh nomor 12 dan ditimbang masing-masing ke dalam cawan petri sebanyak 4 replikasi. Cawan petri dimasukkan ke dalam oven dengan suhu $40^{\circ} \mathrm{C}$ (Gambar 1), dilakukan penimbangan dengan timbangan analitik masing-masing 5 gram pada menit ke-15, 30, 60, 120 dan 180 dicatat hasil penimbangan ${ }^{5,6}$.

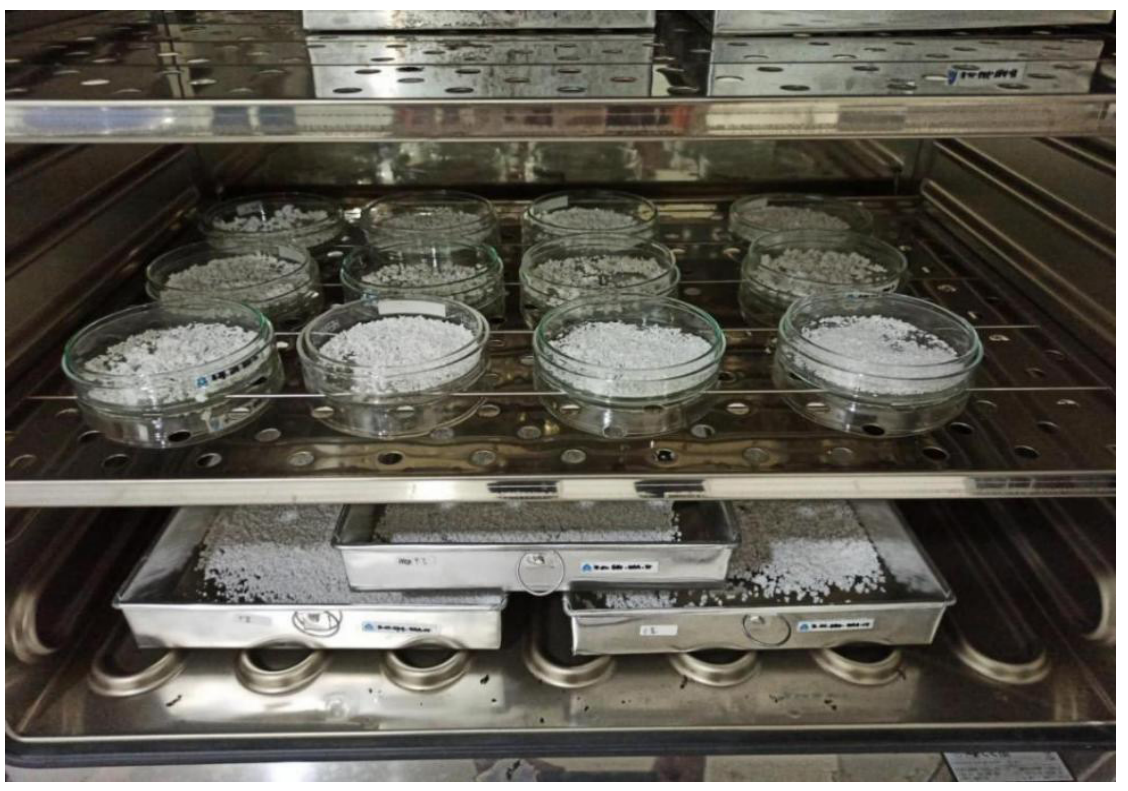

Gambar 1. Pengeringan Granul Paracetamol dengan Oven Memmert UN55

\section{Penentuan LOD dan MC dengan Metode Gravimetri}

Granul paracetamol yang dibuat menggunakan granulasi basah, Gambar 2, menunjukkan bahwa secara organoleptis pada tiga formula granul paracetamol dihasilkan aglomerat atau gumpalan partikel putih merata, tidak rapuh pada saat penimbangan untuk uji LOD dan MC. Dalam proses granulasi, bahan PVP dapat ditambahkan pada pencampuran serbuk dalam keadaan kering dan granulasi basah dengan adanya penambahan air atau aquades ${ }^{3}$. 


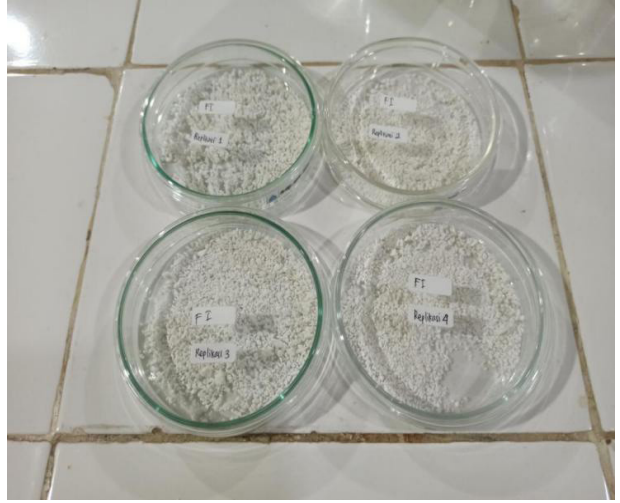

Formula I

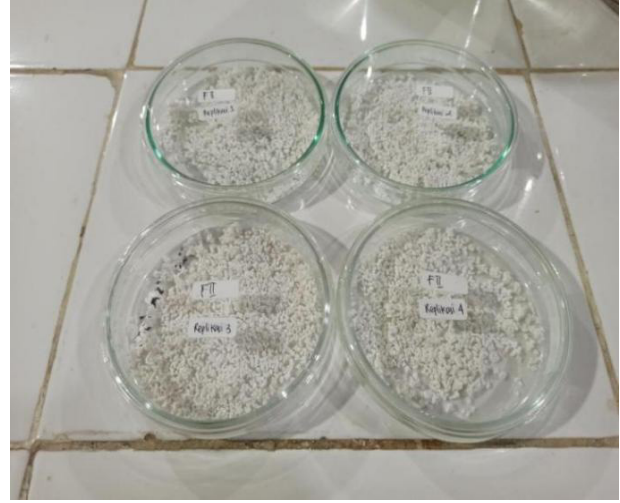

Formula II

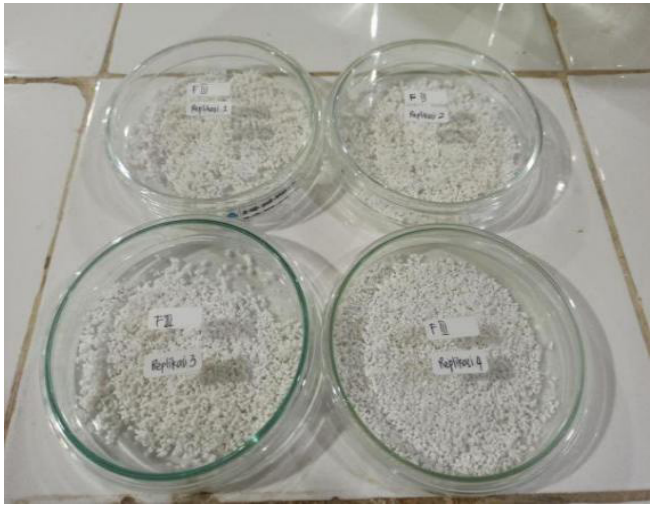

Formula III

\section{Gambar 2. Granul Paracetamol Dengan Variasi Komposisi Bahan Pengisi Laktosa Dan Avicel PH 101}

Uji kadar lembab bertujuan untuk melihat persentase kelembaban yang terdapat pada granul. Hasil penelitian pada Tabel 2 dan Tabel 3, menunjukkan bahwa Formula I (100\% Laktosa) dan Formula III (50\% Laktosa; 50\% avicel PH101) memiliki kandungan lembab $<3 \%$ pada menit ke 120, sedangkan Formula II (100\% avicel PH101) memiliki kandungan lembab < $3 \%$ dinyatakan dengan LOD (2,52\%) dan MC (2,58\%) pada menit ke-60. Formula II merupakan formula yang paling baik untuk digunakan dalam formulasi sediaan tablet paracetamol berdasarkan waktu pengeringan dengan parameter kandungan lembab MC dan LOD. Tabel I dan Tabel II, dapat dinyatakan bahwa granul dari ketiga formula memenuhi persyaratan kadar lembab, karena kadar lembab granul memenuhi syarat apabila $\leq 3 \%$, sehingga granul yang dihasilkan tidak cepat ditumbuhi oleh mikroba, bakteri maupun jamur ${ }^{7,8}$. 
Optimasi Formula pada Granul Paracetamol dengan Variasi Komposisi Bahan Pengisi Laktosa dan Avicel PH 101 Serta Evaluasi Parameter Kadar Lembab Moisture Content dan Loss on Drying

Tabel II. Hasil Pengujian Loss On Drying (LOD) pada Granul Paracetamol Dengan Variasi Komposisi Bahan Pengisi Laktosa Dan Avicel PH 101

\begin{tabular}{|c|c|c|c|c|c|c|c|c|c|c|c|}
\hline \multirow[b]{2}{*}{ Formula } & \multirow[b]{2}{*}{ Replikasi } & \multicolumn{5}{|c|}{ LOD (\%) } & \multicolumn{5}{|c|}{ Rata-Rata LOD (\%) \pm SD } \\
\hline & & $\begin{array}{c}15 \\
\text { menit }\end{array}$ & $\begin{array}{c}30 \\
\text { menit }\end{array}$ & $\begin{array}{c}1 \\
\text { jam }\end{array}$ & 2 jam & 3 jam & $\begin{array}{c}15 \\
\text { menit }\end{array}$ & $\begin{array}{c}30 \\
\text { menit }\end{array}$ & 1 jam & 2 jam & 3 jam \\
\hline \multirow{4}{*}{$\mathrm{F} 1$} & 1 & 8.72 & 6.42 & 3.10 & 0.25 & 0.25 & \multirow{4}{*}{$\begin{array}{c}8.60 \pm \\
0.12\end{array}$} & \multirow{4}{*}{$\begin{array}{c}6.45 \pm \\
0.15\end{array}$} & \multirow{4}{*}{$\begin{array}{c}3.08 \pm \\
0.07\end{array}$} & \multirow{4}{*}{$\begin{array}{c}0.18 \pm \\
0.12\end{array}$} & \multirow{4}{*}{$\begin{array}{c}0.12 \pm \\
0.14\end{array}$} \\
\hline & 2 & 8.48 & 6.61 & 3.07 & 0.00 & 0.00 & & & & & \\
\hline & 3 & 8.68 & 6.25 & 3.00 & 0.24 & 0.00 & & & & & \\
\hline & 4 & 8.51 & 6.52 & 3.16 & 0.23 & 0.23 & & & & & \\
\hline \multirow{4}{*}{$\mathrm{F} 2$} & 1 & 7.08 & 4.21 & 2.57 & 0.00 & 0.00 & \multirow{4}{*}{$\begin{array}{c}7.09 \\
\pm \\
0.07\end{array}$} & \multirow{4}{*}{$\begin{array}{c}4.37 \\
\pm \\
0.17\end{array}$} & \multirow{4}{*}{$\begin{array}{c}2.52 \pm \\
0.14\end{array}$} & \multirow{4}{*}{$\begin{array}{c}0.59 \pm \\
0.41\end{array}$} & \multirow{4}{*}{$\begin{array}{c}0.30 \pm \\
0.24\end{array}$} \\
\hline & 2 & 7.18 & 4.56 & 2.62 & 0.60 & 0.30 & & & & & \\
\hline & 3 & 7.01 & 4.46 & 2.56 & 0.87 & 0.29 & & & & & \\
\hline & 4 & 7.10 & 4.24 & 2.32 & 0.88 & 0.59 & & & & & \\
\hline \multirow{4}{*}{ F3 } & 1 & 9.59 & 7.82 & 5.99 & 0.00 & 0.00 & \multirow{4}{*}{$\begin{array}{c}9.56 \\
\pm \\
0.03\end{array}$} & \multirow{4}{*}{$\begin{array}{c}7.78 \\
\pm \\
0.11\end{array}$} & \multirow{4}{*}{$\begin{array}{c}6.13 \pm \\
0.14\end{array}$} & \multirow{4}{*}{$\begin{array}{c}0.13 \pm \\
0.15\end{array}$} & \multirow{4}{*}{$\begin{array}{c}0.00 \\
\pm 0.00\end{array}$} \\
\hline & 2 & 9.52 & 7.79 & 6.19 & 0.26 & 0.00 & & & & & \\
\hline & 3 & 9.58 & 7.88 & 6.31 & 0.26 & 0.00 & & & & & \\
\hline & 4 & 9.56 & 7.62 & 6.05 & 0.00 & 0.00 & & & & & \\
\hline
\end{tabular}

Tabel III. Hasil Pengujian Moisture Content (MC) pada Granul Paracetamol Dengan Variasi Komposisi Bahan Pengisi Laktosa Dan Avicel PH 101

\begin{tabular}{|c|c|c|c|c|c|c|c|c|c|c|c|}
\hline \multirow[b]{2}{*}{ Formula } & \multirow[b]{2}{*}{ Replikasi } & \multicolumn{5}{|c|}{ MC (\%) } & \multicolumn{5}{|c|}{ Rata- Rata MC (\%) \pm SD } \\
\hline & & $\begin{array}{c}15 \\
\text { menit }\end{array}$ & $\begin{array}{c}30 \\
\text { menit }\end{array}$ & 1 jam & 2 jam & 3 jam & $\begin{array}{c}15 \\
\text { menit }\end{array}$ & $\begin{array}{c}30 \\
\text { menit }\end{array}$ & 1 jam & 2 jam & 3 jam \\
\hline \multirow{4}{*}{ F1 } & 1 & 9.56 & 6.86 & 3.19 & 0.25 & 0.25 & \multirow{4}{*}{$\begin{array}{c}9.41 \pm \\
0.14\end{array}$} & \multirow{4}{*}{$\begin{array}{c}6.89 \pm \\
0.17\end{array}$} & \multirow{4}{*}{$\begin{array}{c}3.18 \pm \\
0.07\end{array}$} & \multirow{4}{*}{$\begin{array}{c}0.18 \pm \\
0.12\end{array}$} & \multirow{4}{*}{$\begin{array}{c}0.12 \pm \\
0.14\end{array}$} \\
\hline & 2 & 9.27 & 7.07 & 3.17 & 0.00 & 0.00 & & & & & \\
\hline & 3 & 9.50 & 6.67 & 3.10 & 0.24 & 0.00 & & & & & \\
\hline & 4 & 9.30 & 6.98 & 3.26 & 0.23 & 0.23 & & & & & \\
\hline \multirow{4}{*}{ F2 } & 1 & 7.62 & 4.40 & 2.64 & 0.00 & 0.00 & \multirow{4}{*}{$\begin{array}{c}7.64 \pm \\
0.08\end{array}$} & \multirow{4}{*}{$\begin{array}{c}4.57 \pm \\
0.18\end{array}$} & \multirow{4}{*}{$\begin{array}{c}2.58 \pm \\
0.14\end{array}$} & \multirow{4}{*}{$\begin{array}{c}0.59 \pm \\
0.42\end{array}$} & \multirow{4}{*}{$\begin{array}{c}0.30 \pm \\
0.24\end{array}$} \\
\hline & 2 & 7.74 & 4.78 & 2.69 & 0.60 & 0.30 & & & & & \\
\hline & 3 & 7.54 & 4.66 & 2.63 & 0.88 & 0.29 & & & & & \\
\hline & 4 & 7.65 & 4.42 & 2.37 & 0.89 & 0.59 & & & & & \\
\hline \multirow{4}{*}{ F3 } & 1 & 10.61 & 8.49 & 6.37 & 0.00 & 0.00 & \multirow{4}{*}{$\begin{array}{c}10.57 \\
\pm 0.04\end{array}$} & \multirow{4}{*}{$\begin{array}{c}8.43 \pm \\
0.13\end{array}$} & \multirow{4}{*}{$\begin{array}{c}6.54 \pm \\
0.16\end{array}$} & \multirow{4}{*}{$\begin{array}{c}0.13 \pm \\
0.15\end{array}$} & \multirow{4}{*}{$\begin{array}{c}0.00 \pm \\
0.00\end{array}$} \\
\hline & 2 & 10.53 & 8.44 & 6.60 & 0.26 & 0.00 & & & & & \\
\hline & 3 & 10.59 & 8.55 & 6.74 & 0.26 & 0.00 & & & & & \\
\hline & 4 & 10.57 & 8.25 & 6.44 & 0.00 & 0.00 & & & & & \\
\hline
\end{tabular}

Pengujian LOD dan MC dilakukan untuk mengukur kadar air granul, dimana semakin banyak air yang terkandung maka akan semakin buruk sediaan yang akan dibuat ${ }^{8}$. Menurut Rowe et al., (2009) dalam Rondonuwu et al., 2017, granul dengan nilai kandungan lembab $\leq 5 \%$ akan menghasilkan granul yang memiliki sifat baik dan stabil saat penyimpanan ${ }^{10,11}$. 
Sebaliknya, jika kadar air dalam granul tinggi, dapat menyebabkan granul menjadi basah dan memiliki daya alir yang buruk, sehingga saat pengemasan akan menjadi sulit ${ }^{12,13}$.

Metode granulasi pada teknologi sediaan padat, dapat digolongkan menjadi tiga kategori utama, yakni proses basah, proses kering (slugging) dan proses lain seperti humidification, priling, melt peletization. Granulasi basah merupakan proses menambahkan cairan (aquadest atau mucilago) pada suatu serbuk atau campuran serbuk dalam suatu wadah yang dilengkapi dengan pengadukan yang akan menghasilkan aglomerasi atau granul basah, sehingga untuk mendapatkan granul dengan kandungan lembab kurang dari 3\%, perlu dikeringkan menggunakan oven atau alat fluidized bed dryer atau yang sering disingkat dengan $\mathrm{FBD}^{14,15}$.

\section{KESIMPULAN DAN SARAN}

Pembuatan tablet paracetamol dengan metode granulasi basah dapat menggunakan bahan pengisi laktosa, avicel PH101 maupun campuran optimum kedua bahan tersebut. Formula 2 dengan bahan pengisi $100 \%$ avicel PH 101 merupakan formula yang paling baik untuk digunakan dalam formulasi granul paracetamol dengan metode granulasi basah berdasarkan kandungan lembab MC dan LOD.

Saran dari hasil penelitian ini adalah perlunya dilakukan optimasi suhu pengeringan untuk penelitian selanjutnya dengan parameter LOD dan MC.

\section{UCAPAN TERIMA KASIH}

Ucapan terimakasih kami sampaikan pada Prodi Sarjana Farmasi dan Laboratorium Teknologi Farmasi, Fakultas IImu-IImu Kesehatan, Universitas Alma Ata yang telah memberikan fasilitas untuk pelaksanaan penelitian granulasi paracetamol dan uji kualitas granul berdasarkan LOD dan MC.

\section{KONFLIK KEPENTINGAN}

Seluruh penulis menyatakan tidak terdapat potensi konflik kepentingan dengan penelitian dan atau publikasi artikel ini.

\section{DAFTAR PUSTAKA}

1. Kementrian kesehatan republik Indonesia. Farmakope Indonesia Edisi V. V. Jakarta: Kementrian Kesehatan Rl; 2014.

2. Agoes, Goeswin. Sediaan Farmasi Padat. Bandung: ITB; 2012.

3. Mulyadi D, Astuti IY, Dhiani BA. Formulasi Granul Instan Jus Kelopak Bunga Rosela (Hibiscus sabdariffa L.) Dengan Variasi Konsentrasi Povidon Sebagai Bahan Pengikat Serta Kontrol Kualitasnya. Pharmacy. 2011;08(03):29-41. 
4. Sweetman S. Martindale. 36th ed. London: The Pharmaceutical, Press; 2009.

5. Ardiani WP. Perbandingan Variasi Suhu Pengeringan Granul Terhadap Kadar Air dan Sifat Fisis Tablet Parasetamol. J Fak Mat dan Ilmu Pengetah Alam. 2012;

6. Wijayati M, Saptarini NM, Herawati IE, Suherman SE. Formulasi Granul Effervescent Sari Kering Lidah Buaya sebagai Makanan Tambahan. ljpst. 2014;1(1):1-6.

7. Somantri A, Kartadarma E, Fitrianingsih P. Formulasi Sediaan Tablet yang Mengandung Ekstrak Etanol Biji Koro Benguk dengan Bahan Pengikat CMC-Na, Amylum Manihot dan Kombinasi Keduanya sebagai Afrodisiak Preparation of Tablets Formulation Containing Velvet Beans Ethanol Extract with evaluasi granu. 2016;(1):343-50.

8. Devi I ayu S. Optimasi Konsentrasi Polivinil Pirolidon (Pvp) Sebagai Bahan Pengikat Tehadap Sifat Fisik Tablet Ekstrak Etanol Rimpang Bangle (Zingiber cassumunar Roxb). J Farm Udayana. 2018;7(2):45.

9. Wahyuni. Pemanfatan Pati Umbi Tire (Amorphophallus onchopillus) sebegai Bahan Pengikat Tablet Parasetamol dengan Metode Granulasi Basah. 2016;1-92.

10. Rowe, C.R., Sheskey, J.P., Quinn EM. Handbook of Pharmaceutical excipients. 6th editio. London: The Pharmaceutical Press; 2009.

11. Rondonuwu C, Citraningtyas G, Sudewi S. Formulasi Tablet Hisap Serbuk Buah Mangga Dodol (Mangifera indica L) dengan Menggunakan Metode Granulasi Basah. Pharmacon. 2017;6(4):110-8.

12. Juita Y. Formulasi tablet effervescent tepung daging lidah buaya. Skripsi. 2008;

13. Lina W, Widiyastuti L, Pramono S, Nugroho AE. Formulasi Granul Kombinasi Ekstrak Terpurifikasi Herba Pegagan (Centella asiatica) (L.) Urban) dan Herba Sambiloto (Andrographis paniculata) (Burm.f.) Nees). Media Farm J Ilmu Farm. 2014;11(2):143-54.

14. Siregar C. Teknologi Farmasi Sediaan Tablet: Dasar-Dasar Praktis. Jakarta: EGC; 2010.

15. Elisabeth V, YamLean PVY, Supriati HS. Formulasi Sediaan Granul Dengan Bahan Pengikat Pati Kulit Pisang Goroho (Musa acuminafe L.) dan Pengaruhnya Pada Sifar Fisik Granul. Pharmacon. 2018;7(4):1-11. 